\title{
Delirium in Cardiac Intensive Care Unit
}

Sukrut Pagad ${ }^{1}$, Manoj R. Somagutta ${ }^{1}$, Vanessa May ${ }^{2}$, Ashley A. Arnold ${ }^{1}$, Saruja Nanthakumaran ${ }^{1}$, Saijanakan Sridharan ${ }^{1}$, Bilal Haider Malik ${ }^{3}$

1. Department of Research, California Institute of Behavioral Neurosciences \& Psychology, Fairfield, USA 2. Department of Research, California Institute of Behavioral Neurosciences \& Psychology, Fairfield, CAN 3. Internal Medicine, California Institute of Behavioral Neurosciences \& Psychology, Fairfield, USA

Corresponding author: Sukrut Pagad,pagadsukrut@gmail.com

\begin{abstract}
Delirium is a multifactorial syndrome and is described as an acute brain dysfunction seen commonly in postcardiac surgery patients. The prevalence of post-operative Delirium (POD) ranges from $11.4 \%$ to $55 \%$, depending on the diagnostic tool and type of study. Confusion Assessment Method for the Intensive Care Unit (CAM-ICU) and the Intensive Care Delirium Screening Checklist (ICDSC) are the two most used and recommended tools by the Society of Intensive Care Medicine. Annual delirium-related healthcare costs in the United States (US) range from 6.6 to 20.4 billion USD in ICU patients. However, delirium in cardiac ICU (CICU) is underdiagnosed and warrants vigorous workup. The risk factors for delirium in CICU can be classified as modifiable, non-modifiable, and cardiac surgical causes. After cardiac procedures, delirium is associated with increased mortality, increased length of hospital stay, loss of functional independence, increased hospital costs, and an independent predictor of death 10 years postoperatively. Nonpharmacological measures such as avoiding delirium-risk medications, early physical rehabilitation, occupational therapy, and sleep improvement strategies have shown significant benefits in decreasing delirium. Pharmacological options are limited for use in CICU, and a need for future studies in this topic is in demand.
\end{abstract}

Categories: Cardiology, Psychiatry, Other

Keywords: delirium, cardiac, icu

\section{Introduction And Background}

According to the Diagnostic and Statistical Manual of Mental Disorders (DSM 5), delirium is characterized by a disturbance in attention (i.e., reduced ability to direct, focus, sustain, and shift attention), awareness (reduced orientation to the environment) or cognition (e.g., disorientation, language, visuospatial ability, or perception) [1]. The prevalence of post-operative delirium (POD) varies from $11.4 \%$ to $55 \%$, depending on the diagnostic tool and type of study [2,3]. According to American Psychiatric Association, the diagnosis needs to be supplemented by observational assessment tools like Confusion Assessment Method (CAM), Confusion Assessment Method - Intensive care unit (CAM-ICU), and Intensive Care Delirium Screening Checklist (ICDSC). These assessment tools will help improve the identification of delirium compared to clinical judgment alone [4].

Received 07/16/2020 Review began 07/27/2020 Review ended 08/28/2020 Published 08/28/2020

\section{() Copyright 2020}

Pagad et al. This is an open access article distributed under the terms of the Creative Commons Attribution License CC-BY 4.0., which permits unrestricted use, distribution, and reproduction in any medium, provided the original author and source are credited.
Despite the many complications, the exact pathophysiology behind POD is unknown though some speculate it could be multifactorial; the effects of anesthesia used during surgery, disruption of the blood-brain barrier due to inflammatory chemokines, decreased cerebral oxygenation, or medications consumed before surgery could contribute $[5,6]$. Delirium is a well-recognized syndrome seen in patients admitted to the medical ward with an illness, ICU, and cardiac surgical wards $[7,8]$. It is an acute transient state that can lead to serious adverse effects if left untreated. Postoperatively, in cardiac patients, delirium is described as acute brain dysfunction. It is associated with increased mortality, increased length of hospital stay, loss of functional independence, increased hospital costs, and, according to Gottesam et al., an independent predictor of death 10 years postoperatively $[2,9,10]$.

Early identification of POD is of utmost importance for the patient's safety. Therefore, this review article aims to provide an overview of the risk factors and prevalence of POD in cardiac surgical patients and suggest appropriate management options. Summarizing current scientific evidence and reports will help clinicians hypothesize possible strategies to prevent post-operative delirium.

\section{Review}

\section{Diagnosis and types}

According to the DSM-5, delirium is defined as a change in mental status, inattention, disorientation, disorganized thinking, disturbed sleep-wake cycle, and altered level of consciousness [1]. The onset of postoperative delirium is frequently acute, mainly one to three days post-surgery. The notable subtypes of delirium are hyperactive, hypoactive, and mixed forms [11] with varying symptom presentations, as demonstrated in Table 1 . The hypoactive being the most common form of delirium as high as $92 \%$ in one 


\section{Cureus}

study, is also associated with increased mortality as it is challenging to diagnose in earlier stages [12]. Postcardiac surgery delirium is identified as a significant postoperative neurologic complication [13]. The incidence of delirium ranges widely (from 3\% to 52\%) in post-cardiac surgery patients depending on the methodology, screening tools, and the type of study $[14,15]$. POD is associated with cognitive decline, prolonged hospital stay, increased hospital costs, institutionalization, physical and emotional stress. Importantly, these patients have a higher risk of mortality within the first years after cardiac surgery $[11,16]$.

\begin{tabular}{|l|l|l|}
\hline Delirium type & Symptoms & Resembles \\
$\begin{array}{l}\text { Hyperactive } \\
\text { Delirium }\end{array}$ & $\begin{array}{l}\text { 1. Hypervigilance 2. Increased arousal 3. Increased psychomotor activity 4. } \\
\text { Agitation 5. Restlessness }\end{array}$ & $\begin{array}{l}\text { 1. Manic 2. Psychotic } \\
\text { decompensation }\end{array}$ \\
$\begin{array}{l}\text { Hypoactive } \\
\text { Delirium }\end{array}$ & $\begin{array}{l}\text { 1. Withdrawn 2. Lethargic 3. Decreased motor activity 4. Apathy 5. Decreased } \\
\text { responsiveness }\end{array}$ & Depression \\
$\begin{array}{l}\text { Mixed motor } \\
\text { type }\end{array}$ & Combination of the above & Rapid cycling \\
\hline
\end{tabular}

TABLE 1: Summary of the types of delirium

\section{Pathogenesis}

The exact pathophysiology behind POD is poorly understood, although many recent studies have attempted to give independent mechanisms that may play a role in the act. However, a spectrum of factors may be responsible for delirium onset [17]. Possible pathways for POD include increased systemic inflammation, changes in neurotransmitters, especially acetylcholine, intraoperative changes, and genetic factors [18-20]. Recent studies exhibit the vital role of microglial activation mediates the pro-inflammatory response, subsequently leading to intense neurological inflammation resulting in POD in cardiac surgery patients $[6,17,21]$.

\section{Risk factors}

Factors involving postoperative delirium (POD), especially related to cardiac surgery, are multifactorial. Intraoperative changes such as cardiac dysfunction, susceptibility to cardiopulmonary bypass, microemboli, rise in the internal body temperature, intravenous $\mathrm{pH}$ paired with changes in the cerebral oxygenation, anesthetics, and cerebral inflammation may precipitate delirium in high-risk individuals [5]. Listed in Figure 1 are the various risk factors associated with delirium seen in patients admitted to the cardiac ICU.

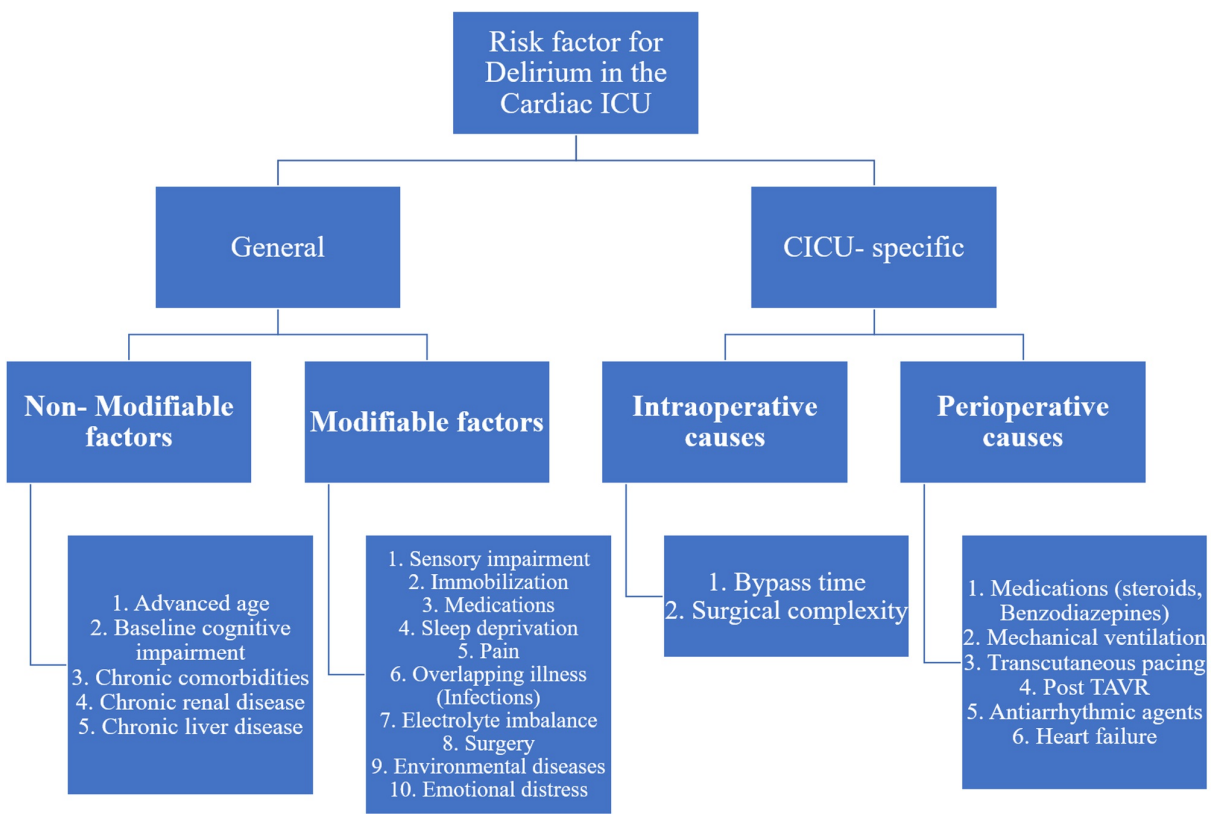

FIGURE 1: Risk factors for delirium in the cardiac ICU

ICU: Intensive Care Unit, CICU: Cardiac Intensive Care Unit, TAVR: Transcatheter aortic valve replacement 
Some authors correlate the systemic inflammatory response, primarily triggered by cardiopulmonary bypass or generation of air microembolism during open-heart surgery, which has an incremental effect in neuropsychological stress response leads to POD [13,22]. Some other authors associate it with advanced atherosclerosis and endothelial dysfunction as a primary source of increased cerebral microembolization risk $[13,23]$.

Intraoperative oxidative injury contributes to oxidative stress, endothelial damage, and acute kidney injury (AKI) [19]. Lopez et al. conducted a prospective study to identify the link between intraoperative hyperoxic cerebral reperfusion and POD. The results infer that intraoperative hyperoxic cerebral reperfusion was independently associated with a $65 \%$ increase in the odds of delirium (odds ratio [OR], 1.65 (1.12 to 2.44); $\mathrm{P}=0.01)[5]$.

Few studies have been done to evaluate the interplay of cerebral flow oxygen and delirium. Imaging techniques such as single-electron emission computed tomography and near-infrared spectroscopy (NIRS), a non-invasive device, are used to measure cerebral brain oxygenation (cerebral oximetry) [6]. This measure also indicates cerebral blood flow; hence it is hypothesized that it may be a possible monitor of delirium.

In a prospective observational study by Mailhot et al., post-cardiac delirium patients are monitored with NIRS three consecutive days after the onset. The authors noticed that the cerebral oximetry levels decreased with the start of delirium and raised back once delirium resorbed. Thus, making cerebral oximetry associated with delirium diagnosis and severity, but not peripheral oximetry [6].

\section{Screening}

Despite the frequent occurrence of delirium in the CICU, it is often underdiagnosed there, which indicates the necessity of standard evaluation in all critically ill patients [24]. In the CICU, screening for delirium requires a more collaborative approach from the cardiologists, nurses, and ICU physicians and other healthcare personnel involved in the patient's care [25].

Generally, the ICU patients may be sedated, intubated, and comparatively sick than non-ICU patients demanding a vigorous workup for delirium. Various screening tools are used in delirium screening in ICU. The commonly used tools are Intensive Care Delirium Screening Checklist (ICDSC), the Confusion Assessment Method for the Intensive Care Unit (CAM-ICU), the Nursing Delirium Screening Scale (NuDESC), the Delirium Detection Score (DDS), Diagnostic and Statistical Manual IV-TR (DSM IV-TR) and the Cognitive Test for Delirium (CTD) [26]. But CAM-ICU and ICDSC are the two most used and recommended tools by the Society of Intensive Care Medicine [25].

In a meta-analysis (including nine studies and 969 patients), CAM-ICU and ICDSC were analyzed for their effectiveness in screening delirium. The authors observed that the sensitivity of the CAM-ICU was $80.0 \%$ (95\% CI: 77.1 to $82.6 \%$ ) and the specificity was $95.9 \%$ (95\% CI: 94.8 to $96.8 \%$ ). The sensitivity of the ICDSC was $74 \%$ ( $95 \%$ CI: 65.3 to $81.5 \%$ ), and the specificity was $81.9 \%$ (95\% CI: 76.7 to $86.4 \%$ ) [27]. In another prospective cohort study, CAM-ICU and ICDSC were evaluated versus the DSM-IV-TR in delirium diagnosis concerning their validity and psychometric properties. They noticed CAM-ICU showed only modest concurrent validity (Cohen's $\mathrm{K}=0.44$ ) and sensitivity $(50 \%)$ but high specificity $(95 \%)$. The ICDSC attained a sensitivity of $63 \%$ and specificity of $95 \%$. Within the CAM-ICU and the ICDSC, ICDSC produced greater sensitivity and specificity ( 78 and $83 \%$ ) with a moderate validity (Cohen's $\mathrm{K}=0.56$ ) compared to CAM-ICU [28]. Thus, a negative test by the CAM-ICU or ICDSC should not negate delirium, and additional workup is required, especially in high-risk patients.

\section{Non-pharmacological measures}

Annual delirium-related healthcare costs in the United States (US) are estimated to range from 6.6 to 20.4 billion USD in ICU patients and 38 to 152 billion USD per year in non-ICU patients. As a result, the focus of management is effective prevention, as therapeutic options are limited. Several management guidelines and standardized programs were developed to prevent, early recognition, and treatment of delirium across ICU and non-ICU settings $[29,30]$. Cost-effective interventions such as setting up clocks and calendars, reminding patients on the current time, place, and date, sleep support by avoiding late-night medication administration, less stressful and quiet environment, and early mobilization are proven to be useful in the non-ICU situations. Cybertherapy or hypnosis, massage, music therapy, cold therapy, relaxation techniques are all recommended for pain management in critically ill-adults [31]. But the evidence lacks how frequent these strategies should be implemented in CICU settings [25].

Delirium progression in the ICU has been associated with sedation and intubation of patients. Earlier studies have proven that frequent interruptions to sedative medications allowing them to wake up and spontaneous breathing strategies have shown decreased mechanical ventilation duration by two days $(\mathrm{p}=0.004)$ and decrease in weaning time also by two days $(\mathrm{p}=0.003)$ [32].

A multicenter cohort study of 15,226 adults in the ICU by Pun et al. demonstrated that complete ABCDE 
bundle (Figure 2) implementation is associated with a lower likelihood of hospital death within seven days (adjusted hazard ratio, 0.32; CI, 0.17-0.62), next-day mechanical ventilation (adjusted odds ratio (AOR), 0.28; CI, 0.22-0.36), coma (AOR, 0.35; CI, 0.22-0.56), delirium (AOR, 0.60; CI, 0.49-0.72), physical restraint use (AOR, 0.37; CI, 0.30-0.46), ICU readmission (AOR, 0.54; CI, 0.37-0.79), and discharge to a facility other than home (AOR, 0.64; CI, 0.51-0.80) [33].

\begin{tabular}{|l|}
\hline A - Assess, Prevent, and Manage Pain, \\
\hline B - Both Spontaneous Awakening Trials (SAT) \\
and Spontaneous Breathing Trials (SBT) \\
\hline C - Choice of analgesia and sedation \\
\hline D - Delirium: Assess, Prevent, and Manage \\
\hline E - Early mobility and Exercise \\
\hline F - Family engagement and empowerment. \\
\hline
\end{tabular}

FIGURE 2: ABCDEF Bundle

SAT: Spontaneous Awakening Trials, SBT: Spontaneous Breathing Trials

Focus on early mobilization in the ICU patients comes with the concern of their safety and efficacy, involvement, and skepticism that they are too sick for participation, but recent studies challenged by implementing early rehabilitation in ICU patients at more initial stages of their stay. Schweickert et al. demonstrated that patients who were randomized to receive early rehabilitation during their ICU stay experienced shorter delirium periods, i.e., two days vs. four days with no rehabilitation $(\mathrm{p}=0.02)$ [34]. Occupational therapy (OT) may also be beneficial in cardiac-ICU patients. A recent study showed a lower delirium incidence in patients with OT exposure than no OT ( $3 \%$ versus $20 \%$, p <0.001) [25]. A study performed by combining physical therapy (PT), OT and low-dose benzodiazepines in medical ICU patients marked a reduced incidence of delirium ( $21 \%$ vs. $53 \%, \mathrm{p}=0.003)$ and a reduction in hospital stay by 3.1 days (95\% CI; 0.3-5.9 days) [25]. Even with the need for further research on the topic, it is prudent to consider that PT and OT are beneficial to ICU patients. It may be challenging to implement these in cardiac ICU patients because of the patients' complexity and added mechanical assistance devices. However, every attempt should be made to implement PT and OT in cardiac ICU patients at the early stages of their stay for beneficial results.

For ICU patients, sleep deprivation is a critical hurdle in which non-pharmacological management strategies become essential. Several techniques, such as reducing the alarm volumes, closing the doors, eye masks, earplugs, and timed turning off lights, have been proved to enhance the patient's sleep in the ICU [1,25]. A systematic review of 10 studies assessed delirium relation after sleep interventions and noticed six studies demonstrated a statistically significant reduction in ICU delirium incidence. Four studies evaluated the duration of delirium, of which three reported a shorter duration of delirium with sleep intervention-two studies associated sleep intervention with a reduced ICU length of stay [35].

\section{Pharmacological management}

Benzodiazepines

Benzodiazepines are associated with an increased risk of delirium ( $\mathrm{OR}=3.0,1.3-6.8)$ [36]. So, a comprehensive search for alternative sedatives mounted, and the use of propofol was evaluated because of its short-acting properties. It has shown better results compared to midazolam by reducing the length of mechanical ventilation [25]. Two studies compared propofol with benzodiazepines and showed a shorter time to light sedation with propofol. Seven randomized controlled trials (RCTs) considered a shortened time to extubation to be clinically significant with propofol [31]. Based on these findings, the Society of Critical Care Medicine proposed practical guidelines, with low quality of evidence that propofol is preferred to 


\section{Cureus}

benzodiazepines for sedation in mechanically ventilated adults after cardiac surgery [31]. However, more RCTs are required comparing benzodiazepines and propofol to evaluate other critical outcomes in the cardiac surgical population.

Antipsychotics

Antipsychotic use as a preventive or therapeutic agent in delirium is acknowledged because of the limitations of using benzodiazepines in delirium patients. But the use of these medications has been uncertain and was associated with limited to no benefit. A large meta-analysis study comparing antipsychotics to placebo or no interventions reported no significant antipsychotics effect on delirium incidence $(\mathrm{OR}=0.56,0.23-1.34)$ [37]. It is also vital to consider the most striking adverse effect of these medication use in cardiovascular patients, which is QT-prolongation and increased mortality risk in demented elderly patients thus resulted in a black-boxed warning by the Food and Drug Administration $[25,38]$

Dexmedetomidine

Dexmedetomidine, an alpha-2 agonist, has sedative properties with an insignificant effect on the respiratory drive and also reduces delirium by more direct neuroprotective mechanisms $[25,31]$. These mechanisms have led to many clinical investigations involving dexmedetomidine in the ICU. Table 3 summarizes the various studies that have shown the significant role dexmedetomidine plays in reducing the risk of delirium developing in cardiac ICU patients.

\begin{tabular}{|c|c|c|c|c|}
\hline Study & Study population & Study Comparison & $\begin{array}{l}\text { Delirium } \\
\text { incidence/outcomes }\end{array}$ & Notes \\
\hline $\begin{array}{l}\text { SEDCOM } \\
\text { trial, 2009, } \\
{[39]}\end{array}$ & $\begin{array}{l}3 / 5 \text { surgical ICU } \\
\text { patients }\end{array}$ & DEX vs. MDX & $\begin{array}{l}\text { DEX vs. MDX ( } 54 \% \text { vs } 76.6 \% \\
\text { p<0.001) }\end{array}$ & Less delirium POD with DEX \\
\hline $\begin{array}{l}\text { Deiner et al. } \\
\text { 2016, [40] }\end{array}$ & $\begin{array}{l}404 \text { surgical } \\
\text { patients }\end{array}$ & Intraoperative DEX vs. NS & $\begin{array}{l}\text { DEX vs. NS }(12.2 \% \text { vs } 11.4 \% \\
p=0.94)\end{array}$ & No difference in POD incidence. \\
\hline $\begin{array}{l}\text { Su X et al., } \\
2016,[41]\end{array}$ & $\begin{array}{l}700 \text { non-cardiac } \\
\text { surgery patients }\end{array}$ & $\begin{array}{l}\text { Postoperative DEX vs. } \\
\text { Placebo }\end{array}$ & $\begin{array}{l}\text { DEX vs. Placebo Odds ratio } \\
(9 \% \text { vs } 23 \% ; p<0.0001)\end{array}$ & Decrease in POD risk with DEX \\
\hline $\begin{array}{l}\text { Shehabi et } \\
\text { al.,2009, [42] }\end{array}$ & 306 & $\begin{array}{l}\text { Postoperative DEX vs. } \\
\text { Morphine }\end{array}$ & $\begin{array}{l}\text { DEX vs. Morphine (8.6\% vs } \\
15 \% ; p<0.088)\end{array}$ & $\begin{array}{l}\text { No decrease in incidence but } \\
\text { decrease in median duration }\end{array}$ \\
\hline $\begin{array}{l}\text { Liu X et al., } \\
2017,[43]\end{array}$ & $\begin{array}{l}\text { Meta-Analysis of } 8 \\
\text { studies }\end{array}$ & $\begin{array}{l}\text { DEX vs. Propofol sedation } \\
\text { after cardiac surgery }\end{array}$ & $\begin{array}{l}\text { DEX vs. Propofol (Risk ratio, } \\
0.40 ; P=.0002) \text {, }\end{array}$ & $\begin{array}{l}\text { DEX decreases POD and shorter } \\
\text { intubation }\end{array}$ \\
\hline
\end{tabular}

TABLE 2: Summarizes a few studies evaluating dexmedetomidine in reducing the risk of delirium in the surgical and ICU population.

DEX: dexmedetomidine, MDX: Midazolam, POD: Postoperative delirium

Statins

The concept of statin use in delirium patients is controversial. The hypothesis behind using statins in delirium is its anti-inflammatory phenotype properties in animal studies that may help neuronal healing rather than neuronal apoptosis by microglial activation [32]. However, a recent meta-analysis observed no favorable effect concerning statins for delirium prevention (RR, 1.03 (95\% CI, 0.68-1.56); $\mathrm{p}=0.89$ ) [44].

\section{Limitations}

This study, however, is subject to a few limitations. Animal studies and the literature published primarily in languages other than English were not considered for this review. Also, many studies in the review are not entirely studied in CICU settings, and reflecting the ICU data and generalizing it with CICU is not always a unique approach.

\section{Conclusions}

Delirium is a multifactorial syndrome, and the erroneous view of delirium as an inevitable consequence of patients' illness in the healthcare team should be discouraged. Every effort should be made to minimize the 
modifiable risk factors of delirium, especially in high-risk patients. Clinicians should be aware of the disease's broad presentation to effectively identify and manage delirium in clinical settings. Implementing effective delirium screening methods is possible with a multidimensional team approach involving all the healthcare members involved in the patient's care, such as nursing-assessments, medical students, and resident physicians' rounds. Screening tools require minimal time and are cost-effective, so they should be performed in all CICU patients at the early stages of their admission.

Due to the limitations in generalizing the standard ICU data to the CICU, it is evident that substantial research is needed to agree or disagree with the present data. More studies are required to provide the effectiveness of early rehabilitation, occupational therapy in CICU patients. More significant clinical trials are necessary to evaluate dexmedetomidine's safety and efficacy, antipsychotics, and statin use in CICU patients with complex cardiovascular diseases.

\section{Additional Information \\ Disclosures}

Conflicts of interest: In compliance with the ICMJE uniform disclosure form, all authors declare the following: Payment/services info: All authors have declared that no financial support was received from any organization for the submitted work. Financial relationships: All authors have declared that they have no financial relationships at present or within the previous three years with any organizations that might have an interest in the submitted work. Other relationships: All authors have declared that there are no other relationships or activities that could appear to have influenced the submitted work.

\section{References}

1. Diagnostic and Statistical Manual of Mental Disorders (DSM- ${ }^{\circledR}$ ) . American Psychiatric Association, Arlington; 2013.

2. Järvelä K, Porkkala H, Karlsson S, Martikainen T, Selander T, Bendel S: Postoperative delirium in cardiac surgery patients. J Cardiothor Vasc Anesth. 2018, 32:4. 10.1053/j.jvca.2017.12.030

3. Mufti HN, Hirsch GM: Perioperative prediction of agitated (hyperactive) delirium after cardiac surgery in adults-the development of a practical scorecard. J Crit Care. 2017, 42:192-9. 10.1016/j.jcrc.2017.07.045

4. Ely EW, Inouye SK, Bernard GR, et al.: Delirium in mechanically ventilated patients: validity and reliability of the confusion assessment method for the intensive care unit (CAM-ICU). JAMA. 2001, 286:2703-2710. 10.1001/jama.286.21.2703

5. Lopez MG, Hughes CG, DeMatteo A, et al.: Intraoperative oxidative damage and delirium after cardiac surgery. Anesthesiology. 2020, 132:551-561. 10.1002/ana.21899

6. Mailhot T, Cossette S, Lambert J, Cournoyer A, Denault AY: Cerebral oximetry as a biomarker of postoperative delirium in cardiac surgery patients. J Crit Care. 2016, 34:17-23. 10.1097/ALN.0000000000003016

7. Inouye SK, Westendorp RG, Saczynski IS: Delirium in elderly people. Lancet. 2014, 383:911-22. 10.1016/S0140-6736(13)60688-1

8. Rudolph JL, Jones RN, Levkoff SE, et al.: Derivation and validation of a preoperative prediction rule for delirium after cardiac surgery. Circulation. 2009, 119:229-36. 10.1161/CIRCULATIONAHA.108.795260

9. Lundström M, Edlund A, Karlsson S, et al.: A multifactorial intervention program reduces the duration of delirium, length of hospitalization, and mortality in delirious patients. J Am Geriatr Soc. 2005, 53:622-8. 10.1161/CIRCULATIONAHA.108.795260

10. Gottesman RF, Grega MA, Bailey MM, et al.: Delirium after coronary artery bypass graft surgery and late mortality. Ann Neurol. 2010, 67:338-44. 10.1111/j.1532-5415.2005.53210.x

11. Gerster PA, Klesse A, Chang J, et al.: Neurological complications in cardiac surgery. Curr Anesthesiol Rep. 2019, 9:223-233.

12. McPherson JA, Wagner CE, Boehm LM, et al.: Delirium in the cardiovascular ICU: exploring modifiable risk factors. Crit Care Med. 2013, 41:405-413. 10.1097/CCM.0b013e31826ab49b

13. Kotfis K, Szylińska A, Listewnik M, et al.: Early delirium after cardiac surgery: an analysis of incidence and risk factors in elderly ( $\geqslant 65$ years) and very elderly ( $\geqslant 80$ years) patients. Clin Interv Aging. 2018, 13:10611070. 10.2147/CIA.S166909

14. Chaud GJ, Simon MB, Filippa PA, et al.: Is the risk of delirium reduced in minimal invasive cardiac surgery . J Cardiol Cardiovasc Ther. 2019, 14:555879. 10.19080/JOCCT.2019.14.555879

15. Lee A, Mu JL, Joynt GM, et al.: Risk prediction models for delirium in the intensive care unit after cardiac surgery: a systematic review and independent external validation. Br J Anaesth. 2017, 118:391-399. 10.1093/bja/aew476

16. Saczynski JS, Marcantonio ER, Quach L, et al.: Cognitive trajectories after postoperative delirium. N Engl J Med. 2012, 367:30-39. 10.1056/NEJMoa1112923

17. Brown CH: Delirium in the cardiac surgical ICU. Curr Opin Anaesthesiol. 2014, 27:117-122. 10.1097/ACO.0000000000000061

18. Rudolph JL, Ramlawi B, Kuchel GA, et al.: Chemokines are associated with delirium after cardiac surgery . J Gerontol A Biol Sci Med Sci. 2008, 63:184-189.

19. Billings FT, Pretorius M, Schildcrout JS, et al.: Obesity and oxidative stress predict AKI after cardiac surgery. J Am Soc Nephrol. 2012, 23:1221-1228. 10.1681/ASN.2011090940

20. Adamis D, Van Munster BC, Macdonald AJ: The genetics of deliria . Int Rev Psychiatry. 2009, 21:20-29. 10.1080/09540260802675510

21. Cunningham C: Systemic inflammation and delirium: important co-factors in the progression of dementia . Biochem Soc Trans. 2011, 39:945-953. 10.1042/BST0390945 
22. Cerejeira J, Firmino H, Vaz-Serra A, Mukaetova-Ladinska EB: The neuroinflammatory hypothesis of delirium. Acta Neuropathol. 2010, 119:737-754. 10.1042/BST0390945

23. Rudolph JL, Babikian VL, Birjiniuk V, et al.: Atherosclerosis is associated with delirium after coronary artery bypass graft surgery. J Am Geriatr Soc. 2005, 53:462-466. 10.1111/j.1532-5415.2005. 53165.x

24. Van Eijk MM, van Marum RJ, Klijn IA, de Wit N, Kesecioglu J, Slooter AJ: Comparison of delirium assessment tools in a mixed intensive care unit. Crit Care Med. 2009, 37:1881-1885. 10.1097/CCM.0b013e3181a00118

25. Ibrahim K, McCarthy CP, McCarthy KJ, et al.: Delirium in the cardiac intensive care unit. J Am Heart Assoc. 2018, 7:008568. 10.1161/JAHA.118.008568

26. Brummel NE, Vasilevskis EE, Han JH, Boehm L, Pun BT, Ely EW: Implementing delirium screening in the ICU: secrets to success. Crit Care Med. 2013, 41:2196-2208. 10.1097/CCM.0b013e31829a6f1e

27. Gusmao-Flores D, Salluh JI, Chalhub RÁ, Quarantini LC: The confusion assessment method for the intensive care unit (CAM-ICU) and intensive care delirium screening checklist (ICDSC) for the diagnosis of delirium: a systematic review and meta-analysis of clinical studies. Crit Care. 2012:115-2012. 10.1186/cc11407

28. Boettger S, Nuñez DG, Meyer R, et al.: Delirium in the intensive care setting: a reevaluation of the validity of the CAM-ICU and ICDSC versus the DSM-IV-TR in determining a diagnosis of delirium as part of the daily clinical routine. Palliat Support Care. 2017, 15:675-683. 10.1017/S1478951516001176

29. Milbrandt EB, Deppen S, Harrison PL, et al.: Costs associated with delirium in mechanically ventilated patients. Crit Care Med. 2004, 32:955-962. 10.1097/01.CCM.0000119429.16055.92

30. Leslie DL, Marcantonio ER, Zhang Y, Leo-Summers L, Inouye SK: One-year health care costs associated with delirium in the elderly population. Arch Intern Med. 2008, 168:27-32. 10.1001/archinternmed.2007.4

31. Devlin JW, Skrobik Y, Gélinas C, et al.: Clinical practice guidelines for the prevention and management of pain, agitation/sedation, delirium, immobility, and sleep disruption in adult patients in the ICU. Crit Care Med. 2018, 46:825-873. 10.1097/CCM.0000000000003299

32. Hipp DM, Ely EW: Pharmacological and nonpharmacological management of delirium in critically ill patients. Neurotherapeutics. 2012, 9:158-175. 10.1007/s13311-011-0102-9

33. Pun BT, Balas MC, Barnes-Daly MA, et al.: Caring for critically ill patients with the ABCDEF bundle: results of the ICU Liberation Collaborative in over 15,000 adults. Crit Care Med. 2019, 47:3-14. 10.1097/CCM.0000000000003482

34. Schweickert WD, Pohlman MC, Pohlman AS, et al.: Early physical and occupational therapy in mechanically ventilated, critically ill patients: a randomised controlled trial. Lancet. 2009, 373:1874-1882. 10.1016/S0140-6736(09)60658-9

35. Flannery AH, Oyler DR, Weinhouse GL: The impact of interventions to improve sleep on delirium in the ICU: a systematic review and research framework. Crit Care Med. 2016, 44:2231-2240. 10.1097/CCM.0000000000001952

36. Clegg A, Young JB: Which medications to avoid in people at risk of delirium: a systematic review . Age Ageing. 2011, 40:23-29. 10.1093/ageing/afq140

37. Neufeld KJ, Yue J, Robinson TN, Inouye SK, Needham DM: Antipsychotic medication for prevention and treatment of delirium in hospitalized adults: a systematic review and meta-analysis. J Am Geriatr Soc. 2016, 64:705-714. 10.1111/jgs.14076

38. Meeks TW, Jeste DV: Beyond the black box: what is the role for antipsychotics in dementia? . Curr Psychiatr. 2008, 7:50-65.

39. Riker RR, Shehabi Y, Bokesch PM, et al.: Dexmedetomidine vs midazolam for sedation of critically ill patients: a randomized trial. JAMA. 2009, 301:489-499. 10.1001/jama.2009.56

40. Deiner S, Luo X, Lin HM, et al.: Intraoperative infusion of dexmedetomidine for prevention of postoperative delirium and cognitive dysfunction in elderly patients undergoing major elective noncardiac surgery: a randomized clinical trial. JAMA Surg. 2017, 152:171505. 10.1001/jamasurg.2017.1505

41. Su X, Meng ZT, Wu XH, et al.: Dexmedetomidine for prevention of delirium in elderly patients after noncardiac surgery: a randomised, double-blind, placebo-controlled trial. Lancet. 2016, 388:1893-1902. 10.1016/S0140-6736(16)30580-3

42. Shehabi Y, Grant P, Wolfenden H, et al.: Prevalence of delirium with dexmedetomidine compared with morphine-based therapy after cardiac surgery: a randomized controlled trial (DEXmedetomidine COmpared to Morphine-DEXCOM Study). Anesthesiology. 2009, 111:1075-1084. 10.1097/ALN.0b013e3181b6a783

43. Liu X, Xie G, Zhang K, et al.: Dexmedetomidine vs propofol sedation reduces delirium in patients after cardiac surgery: a meta-analysis with trial sequential analysis of randomized controlled trials. J Crit Care. 2017, 38:190-196. 10.1016/j.jcrc.2016.10.026

44. Vallabhajosyula S, Kanmanthareddy A, Erwin PJ, Esterbrooks DJ, Morrow LE: Role of statins in delirium prevention in critical ill and cardiac surgery patients: a systematic review and meta-analysis. J Crit Care. 2017, 37:189-196. 10.1016/j.jcrc.2016.09.025 